\title{
Research on Constraints and Countermeasures for the Development of Outdoor Sports Tourism in Hubei Province
}

\author{
Lun Li, Shisi Zou \\ Physical Education Department (Wuhan) \\ of China University of Geosciences, \\ Wuhan, Hubei 430074
}

\begin{abstract}
This paper analyzes the constraints and countermeasures for the development of outdoor sports tourism industry in Hubei province by using literature method and expert interview method, with the aim to supply guidance for the fast development of outdoor sports tourism in Hubei province. Constraints: unclearness of development ideas, lack of market management norms, lack of professional agents and uncertainty of market prospect; Suggestions: investigate the reserve of natural resources that can be used for outdoor sports in Hubei province as soon as possible to offer theoretical basis for the scientific development of outdoor sports tourism, size up current situation of outdoor sports tourism market in Hubei as soon as possible, actively guide travel agencies and outdoor sports clubs to develop outdoor sports travels, realize scientific planning and reasonable layout, make use of transportation conditions to promote the construction of outdoor sports tourism industrial cluster, and broaden the ways of thinking and make plans carefully.
\end{abstract}

Keywords- outdoor sports tourism industry, constraints, research of countermeasures, Hubei province.

\section{BACKGROUND}

Hubei province is located in central China, famous as the thoroughfare of nine provinces, and it's endowed with rich natural resources for outdoor sports. In its territory, there are 1195 rivers longer than $5 \mathrm{~km}$, more than 700 lakes (almost over 3000 square kilo meters) and 156.3 hectares wet land in addition to the famous natural landscapes, such as Yangtze River, Han River, Wudang Mountain and Shennongjia Virgin Forest. In its east, west and north parts, there are hilly and mountainous areas. Natural outdoor sports fields with waters, mountains and gullies can be seen everywhere. In China University of Geosciences (Wuhan), Wuhan University and other universities in this province, many outdoor sports teaching sites including abseiling, orienteering and outward training have been planned just based on the natural resources in campus. Many universities in Hubei province including China University of Geosciences (Wuhan) have launched professional talents training program and thus rich professional human resources in outdoor sports have been accumulated here, thus the "Hubei Phenomenon" that will bring surprises to the industry is bred in this land. There are already 23 registered outdoor sports clubs (quantity of the unregistered is unknown), 5 of which have been awarded the title of "China Top Ten Outdoor Sports Clubs" for more than ten times accumulatively.

"Rise of Central China" strategy has stimulated the economic development of Hubei province and tourism demand of residents in the province is greatly increased with the rise of incomes. In 2008, only tourists from this province reached 51.09 million. The policy of "resource-conserving \& environmental-friendly society" requires Hubei to transform its economic development pattern, that is, gradually increasing the contribution of service industry. Strengthening the development of tourism industry is of great strategic significance. The provincial Party committee secretary Mr. Luo Qingquan (2010) emphasized to "quicken the cultivation of pillar tourism industries and make great efforts to make Hubei a powerful province in tourism”. Under such background, the Provincial Sports Bureau proposed to construct "sports tourism economic circle" in Hubei province and create "biological tourism cultural circle" in its western area, all taking outdoor sports as the theme, for example, angling at Honglian Lake, drifting at Jiuwan Rivulet, adventuring at Savage Valley, Skiing at Shennongjia and outward training at Shuangfeng Mountain National Forest Park have become brands among the public. The adventure tourism area at Qianjiaping, Shennongjia was accredited as one of key investment attracting tourism projects of Hubei province in 2010 and phase-II project of the ski field at Shennongjia has been commenced.

Survey finds that, under such good development momentum, outdoor sports industry has began to arouse widespread concerns, but the development of outdoor sports tourism lags behind and the organic connection of "market demand - travel agent - outdoor sports tourism resource in and out of Hubei province" hasn't been established. The establishment of outdoor sports tourism industry chain is a major way to make full use of outdoor sports landscapes and exploit market value and also an important issue that needs to be studied urgently.

\section{OVERVIEW OF OUTDOOR SPORTS TOURISM INDUSTRY}

Outdoor sports refer to all kinds of activities people do at spare time in form of sports (hiking, skiing, climbing, bicycle driving etc.) in various natural environments 
including mountainous area, waters, deserts and plateaus for the purpose of physical exercise, leisure and rest, interpersonal relationship, excitement and adventure (Li Hongyan, 2004). So, outdoor sports tourism means the travels for such kinds of purposes and it's a special type of sports tourism. Compared with traditional tourism in which tourists only have a glimpse of the sceneries, outdoor sports tourism focuses on tourists' participation and tourists can enter the cave, go through the forest and climbing onto the peak personally and therefore get the experiences of coming close to the nature, feeling the nature and integrating into the nature.

Outdoor sports tourism has been listed into major choices of tourists. One survey of General Administration of Sports shows that: $75 \%$ of tourists have a travel for the purpose of physical exercise, recovery and leisure, but the revenues of sports tourism in China only takes up $5 \%$ in the total revenues of tourism industry (outdoor sports tourism takes up a smaller portion), while it reaches $25 \%$ in developed countries. As estimated by insiders, the population participating in outdoor sports in China has exceeded ten million (Li Shuping, 2005). Outdoor sports has gradually become a new part of urban life and outdoor sports tourism that is greatly distinguished from the traditional sightseeing tourism for its strong participation will become an important driving force to promote the development of sports tourism in China.

The development of outdoor sports industry drives outdoor sports tourism. In Guizhou province, under the driving force brought by the development of outdoor sports, the residents at Getu River Scenic Area of Ziyun County, Xiasi Town of Majiang County, and Shibing County of Qiandongnan Prefecture have threw off poverty, for example, the rock climbing competition held at Getu Scenic Area in 2007 attracted 226, 000 tourists in the whole year, but volume of tourists in 2003 was only 80,000 . Another example is the canoe slalom competition held at Xiasi Town, Majiang County, which also brought a sharp increase of tourists, reaching 182,000 in 2006 and rising to 430,000 in 2009 in this county. The development of outdoor sports tourism has great marginal effects since it can drive the development of retailing, manufacturing, transportation, foods and other related industries. As estimated by insiders, one outdoor sports self-guided traveler spends at least 3000 Yuan in the outfit. Thus development of outdoor sports tourism is of great significance to social and economic construction.

Outdoor sports tourism industrialization is an important measure to normalize this market. Nowadays in China, outdoor sports accident insurance is only sold to organizations, which leads to the fact that it was difficult for outdoor sports self-guided travelers to get compensation in the frequent injury accidents in recent years. On one hand, the public has great demand of outdoor adventure; on the other hand, proper system guarantee hasn't been in place, which increases the risk of outdoor sports and prohibits the development of outdoor sports industry. Uniform organization of outdoor sports tourism activities by tourist agents, which can be realized through outdoor sports tourism industrialization, will be an important channel to safeguard the sound development of outdoor sports tourism market.

\section{Advantages of Hubei Province to Develop OUTDOOR SPORTS TOURISM}

\section{A. Natural Resources}

There are mainly hills and mountains in the territory of Hubei with abundant of natural resources for outdoor sports. Mountains, rivers and lakes can be found everywhere at Enshi, Shiyan, Huangmei and Qichun of this province, thus there are many places here suitable for camping, trails, hiking, river tracing, adventuring etc. China University of Geosciences, Wuhan University, Huanggang Normal University, Xianning College, Huazhong University of Science and Technology provide outdoor sports courses mainly using natural resources in the province. The rich natural resources for outdoor sports buried in Dabie Mountain Area, Dazhi and western Hubei area are awaiting development.

\section{B. Human Resources}

The professional talents in outdoor sports from China University of Geosciences (Wuhan) and other universities and colleges will supply sufficient human resources for the development of outdoor sports tourism in Hubei province. At the same time, a batch of outdoor sports clubs has grown up in Hubei after over ten years' development and the human resources stored in the clubs will facilitate the construction of outdoor sport tourism industry. After receiving proper training on tourism business, these high-quality talents will be able to shoulder the tasks to develop outdoor sports tourism in Hubei province.

\section{Social Environment}

Although the concept of "outdoor sports tourism industry" hasn't been proposed in Hubei, outdoor sports tourism landscape construction has been included in the development plan of sports industry as an important part. To fully develop the social and economic values of these landscapes, it's an inevitable course to introduce market demand into tourism areas via tourism industry. Since there are abundant of resources suitable for outdoor sport tourism in Hubei province, e.g. only drifting fields total up to 12 (many more are under construction), professional design of outdoor sports tourism industry and integration of tourism products is necessary to facilitate the reasonable development of outdoor sports tourism industry in Hubei by combining industrial construction, market development and environmental protection.

\section{CONSTRAINTS FOR DEVELOPMENT OF OUTDOOR SPORTS TOURISM IN HUBEI}

Nowadays, outdoor sports tourism is still a new concept. Government organs at all levels in Hubei province are indeed developing several construction projects relating to outdoor sports tourism, but the 
development strategy of outdoor sports tourism industry hasn't been established from the strategic perspective. It's concluded through comprehensive analysis that the constraints for the development of outdoor sports tourism industry in Hubei include:

\section{A. Ideas of development are not definite}

Although outdoor sports tourism is a sunrise industry, government organs haven't established definite ideas of development. Without guidance from functional government organs, the outdoor sports tourism in Hubei province now mainly focus on the development of natural resources and construction of hardware facilities, but market development and products development haven't arrive at certain scale and the practitioners in this industry are very less. In other words, the lack of policy guidance may be the main reason that outdoor sports tourism industry develops slowly in Hubei province, and in essence, it is because functional government organs of Hubei still has no clear judgment about its development prospect. So deep study of this issue will be the basis for the decisions of related functional organs and will be of great practical significance to promote the development of outdoor sports tourism industry in Hubei province.

\section{B. Market management norms are not in place}

Through an investigation conducted among many outdoor sports clubs of the province, it's found that outdoor sports tourism is mainly in form of self-guided travel, which leads to: (1) market value of resource reserve can't be embodied; (2) nonstandard market operations increase the risk of tourists. Strengthening the construction of outdoor sports tourism and connecting tourists with tourism resources via intermediate agents to offer opportunity for outdoor sports accidence insurance to enter market can facilitate market normalization to form mature industrial chain and also decrease the risks of tourists participating in outdoor sports.

\section{Professional agents are not in place}

Presently, such clubs in the province rarely organize outdoor sports tourism activities, the only one who engage in outdoor sports industry is China Youth Travel Service (CYTS), but what CYTS focuses on is outward training. I envisage that: tourists can go hiking at Enshi, fishing at Honghu, climbing at Mulan Mountain and camping at Dabie Mountain in spring, go drifting, river tracing, adventuring by entering caves and fishing by stepping into rivers in summer, encamp at the Himalayas in autumn, and go ice climbing and skiing in northern areas in winter. The lack of agents makes it difficult to form such industrial development pattern.

\section{Market prospect is uncertain}

"Rise of Central China" strategy has stimulated the economic development of Hubei province and tourism demand of residents in the province is greatly increased with the rise of incomes. In 2008, only tourists from this province reached 51.09 million. One survey conducted by
General Administration of Sports shows that: $75 \%$ of tourists have a travel for the purpose of physical exercise, recovery and leisure, but the revenues of sports tourism in China only takes up 5\% in the total revenues of tourism industry (outdoor sports tourism takes up a smaller portion), while it reaches $25 \%$ in developed countries. In addition, foreign experience in development of outdoor sports tourism also proves that it's a sunrise industry. But investment is always accompanied with risk. The analysis of prospect and feasibility of outdoor sports tourism hasn't been reported. At such a time that investors are not confident with this industry, it's necessary to have a careful investigation on development situation and prospect of outdoor sports tourism in Hubei province and offer supports as soon as possible for this sunrise industry.

\section{V.COUNTERMEASURES FOR THE DEVELOPMENT OF OUTDOOR SPORTS TOURISM IN HUBEI PROVINCE}

Guizhou province, Chongqing city, Qingdao city and other places’ proven experience in developing outdoor sports tourism suggests that this industry is of great economic and social value. Hubei province is endowed with rich natural resources that can be developed for various outdoor activities such as, river tracing, drifting, camping, hiking, climbing, adventuring and orienteering. On top of that, tourist agents in Hubei province can also organize climbing, skiing and other activities in other provinces. With the development of China's economy, outdoor activities have gradually become the new favorite of tourists. This is especially true for people who have become the mainstream of the society as they accept the emerging culture and are more willing to have a new mental experience in the open even if it means to put their lives at risk. In this context, if we can standardize the outdoor sports market, add more tourism items to the "itinerary", and enhance the safety of travelling, outdoor sports will be more favored by the public.

The unique and rich natural endowments that Hubei province boasts for the development of outdoor sports tourism should be tapped into at an earliest date in order to become an important outdoor sports tourism center in China. To strive for this goal, we must fully capitalize on the natural, human and social resources that can contribute to the development of outdoor sports tourism. When that is achieved, the economic and social development of Hubei province can also be enhanced.

Based on the results of previous studies, we make the following suggestions:

(1) Investigate the reserve of natural resources that can be used for outdoor sports in Hubei province as soon as possible to offer theoretical basis for the scientific development of outdoor sports tourism;

(2) Size up the current situation of outdoor sports tourism market in Hubei as soon as possible, including public demand for outdoor sports travel, the different kinds of outdoor sports travel programs offered by travel agencies and outdoor sports clubs, natural landscapes available for the development of outdoor sports tourism and to what extent these landscapes have been developed 
for outdoor sports tourism. In addition, investigate the quality of outdoor sports tourism products in other provinces. These efforts combined can offer a theoretical basis for establishing a sound Hubei outdoor sports tourism development strategy.

(3) Actively guide travel agencies and outdoor sports clubs to develop outdoor sports travels, help them to design reasonable products, and give them policy assistance in order to build a professional team of outdoor sports travel agents as soon as possible, thus paving the way for further development of outdoor sports tourism in Hubei.

(4) Adhere to scientific planning and reasonable layout. While developing natural resources and the outdoor sports tourism industry, we must see to it that economic benefits, social effects and environmental impacts are balanced, and that industrial development go together with environmental protection.

(5) Make use of transportation conditions to promote the construction of outdoor sports tourism industrial clusters. Strengthen the link both inside and outside a quarter to avoid unnecessary duplication and to offer supreme tourism products with distinctive features and rich endowments.

(6) Broaden the ways of thinking. Strive to build Hubei an important central hub of outdoor sports tourism in China by fully leveraging the resources in Hubei, while at the same time actively discovering and developing resources in other provinces.

(7) Make plans carefully. Promote the development of outdoor sports tourism step by step until it becomes a developed multi-functional industrial chain. Outdoor sports tourism has marginal effect and spinoff effect on other industries. Since right now we are at an initial stage of outdoor sports tourism development and at a time when many coastal industries are moving to the mainland, we can seize this opportunity to facilitate the development of outdoor sports tourism in Hubei, which will in turn promote the development of many other industries in this province, such as retail \& manufacturing industries and competition events.

The favorable geographic location of Hubei and rich reserve of natural resources that can be developed for outdoor sports in this province present a natural competitive advantage in outdoor sports tourism industry. We should not only focus on the development of our natural resources and take advantage of the current trend of social development to build a strong outdoor sport tourism industry in Hubei, but also should be more confident and determined to realize the goal of becoming the center of outdoor sports tourism in China, and even the center of the whole outdoor sports industry. The development of outdoor sports tourism is expected to act as a lever that drives the development of the whole outdoor sports industry in China.

\section{REFERENCES}

[1] Jianming Li. Research on Construction of Sports Tourism Economic Circle in Hubei Province [EB/OL]. http://www.sport.gov.cn.2009-5-24.

[2] Kaifeng Luan and Zhijian Zhang. Investigation Report about Outdoor Sports Clubs in Hubei Province [EB/OL]. http://cmasports.sport.org.cn.2006-6-22.

[3] Decision of Hubei Provincial Committee of the CPC and People's Government on Quickening the Cultivation of Pillar Tourism Industries and Promoting the Construction of a Powerful Province in Tourism [EB/OL]. http://www.hubeitour.gov.cn.2010-8-23.

[4] Hongyan Li. Research on Theory and Practice of Outdoor Sports [D]. Beijing Sport University, 2006.

[5] Guangyan Wang. Survey and Research on Development of Sports Tourism in Western Hubei Province [J]. Journal of Jinlin Institute of Physical Education, 2004, 20 (2): 31, 42.

[6] Fengxiang Liu. Concepts of Outdoor Sports and Sports Tourism and Analysis of Their Relation [J]. Journal of Wuhan Institute of Physical Education, 2008, 42 (5): 74-78.

[7] Jiuquan Li and Jie Gao. Research on Current Situation of and Countermeasures for Chinese Outdoor Sports Industry [J]. Journal of Beijing Sport University, 2008, 31 (12): 1625-1627, 1676.

[8] Tourism Bureau of Hubei Province. Report of Statistics on Hubei Province Tourism Industry in 2008 [EB/OL]. http://www.hubeitour.gov.cn.2010-8-28. 